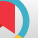

\title{
Direct Relationship Between Sleep Disorder and Depression Severity in Iranian Adolescents
}

\author{
Azar Pirdehghan ${ }^{1,{ }^{*}}$, Somayeh Babaveisi ${ }^{2}$ and Soheila Panahi ${ }^{3}$ \\ ${ }^{1}$ School of Public Health and Research Center for Health Sciences, Hamadan University of Medical Sciences, Hamadan, Iran \\ ${ }^{2}$ Department of Community and Preventive Medicine, School of Public Health and Research Center for Health Sciences, Hamadan University of Medical Sciences, Hamadan, \\ Iran \\ ${ }^{3}$ Department of Psychiatry, School of Medicine, Hamadan University of Medical Sciences, Hamadan, Iran \\ "Corresponding author: Department of Community and Preventive Medicine, School of Public Health and Research Center for Health Sciences, Hamadan University of Medical \\ Sciences, Hamadan, Iran. Email: pirdehghan93@gmail.com
}

Received 2020 April 19; Revised 2020 June 11; Accepted 2020 August 20.

\section{Abstract}

Background: Sleep pattern is one of the most important issues which can affect mental development in adolescents.

Objectives: This study was designed to asses sleep pattern and its relationship with depression in order to obtain information for planning interventional programs and health promotion in adolescents.

Methods: This was a cross-sectional study conducted on high school students in Hamadan, Iran in 2019. Mean age of the students was $16.53 \pm 0.69$ years (Min - Max: 15 - 19), and 290 (50.3\%) students were girls. Samples were selected by multiple cluster sampling method in which 576 students were enrolled in the study. Two standard, valid and reliable self-reported questionnaire was used for recording sleep pattern (PSQ) and depression (Beck). After data collection, SPSS was used for data analysis. All P values less than 0.05 were considered as significant.

Results: Nearly 70\% of the adolescents had problems in some subscales of sleep disorder included in mental quality of sleep, delay in falling asleep and daily dysfunction. Among them in 10\% sleep duration was less than 5 hours and in $69 \%$ usual bedtime was after midnight (24 o'clock). Severe sleep problem in boys and students with fine educational status was more than others (P value $<$ 0.001 ) and there was a statically significant correlation between sleep disorder and depression score (Pearson correlation: $r=0.42$; $\mathrm{P}<0.001$ ) and in students with severe sleep disorder, $48.9 \%$ were severely depressed.

Conclusions: Problems in mental quality of sleep was notable in Iranian adolescents, almost half of them had some degree of depression symptoms. Being boy and having severe problem in sleep pattern were predictors for depression. This information might be applied for well-being as well as physical and mental development interventional programs such as sleep health screening and adolescents and their parents' educational programs in adolescents' health promotion sector.

Keywords: Adolescent, Sleep Disorders, Depression

\section{Background}

Proper sleep pattern is considered as an important effective factor on physical and mental development of adolescents and children (1-4). So, the trend of insufficient and poor quality sleep among adolescents is a public health concern which assessed its relationship with several mental problems such as depression, anxiety, social isolation and attention deficit hyperactivity disorders (ADHD) (5-8) and physical disorders included in hypertension, hyperglycemia and obesity (9) in adolescents.

Depression is the second most common cause of mortality among adolescents because it can lead to suicide (10-12). In other words, sleep disturbance is considered among the top 10 warning signs of suicide in adolescence
(13). So, these two important issues can highlight potential importance of assessment of relationship between sleep and depression in this critical period of growing up from childhood into adulthood when social interactions become more complex.

Modifying deteriorated sleep may be protective factor in prevention of mental problems including depression in adolescence $(4,14)$.

Findings from studies on relationship between sleep and psychological functions in adolescents have shown that adolescents and their parents should be educated about poor sleep and the effects of sleepiness on psychological problems and they must be awarded about some symptoms such as anxiety, depression, and somatic complaints and guidance about monitoring sleepiness (15). 
Neurobiological studies declare that sleep deprivation may reduce inhibition of the amygdala area and can affect emotional processing and progression of anxiety, depression and social isolation, gradually $(16,17)$.

Beside the biological mechanisms, cultural factors such as co-sleeping, bedtime rituals, the sleeping environment and napping, are also important determinants of sleep behaviors in adolescents and influence both the type and frequency of sleep problems (18).

Previous studies have shown that sleep might be a modifiable risk factor in prevention of several mental health problems in adolescence $(19,20)$.

\section{Objectives}

Therefore, this study was designed to asses sleep pattern and its relationship with depression. It might be helpful for designing next strong cohort studies for evaluating a causal association between sleep pattern and depression in order to apply helpful information for well-being and physical and mental development interventional programs in adolescents health promotion as an important age group in the future by policy makers.

\section{Methods}

In 2019 April to August we arranged a cross-sectional survey in 3 levels of high schools (10th, 11th and 12th level) in Hamedan province located in North West part of Iran. Students in consenting schools were in randomly multiple cluster selected classes. Of the 700 students from 20 classes eligible to participate, 567 completed the questionnaire, for a response rate of $82 \%$. Missing values were removed from calculations and statistical analysis. All 10th, 11th and 12th level high school students studying in Hamadan in 2019 were included and lack of willingness and written consent of containedn the study was considered as exclusion criteria.

We applied a self-reported questionnaire consisting4 parts. The First part of questionnaire contained demographic questions. In the second part we applied PSQI, a standard self-reported valid and reliable ( $\alpha: 0.83)$ questionnaire for recording sleep quality (21). All questions could be answered by a 3-level scale (never, sometimes ( 2 or 3 times in a week), often (more than 3 times in a week)). A standard instruction was used for determining the score of sleep quality in different subscales and severity of sleep disorder.

Beck Depression Inventory questionnaire as a valid and reliable questionnaire was used in the third part for measuring depression. The internal consistency was demonstrated to be 0.9 and the retest reliability ranged from
0.73 to 0.96 (22), educational status was defined based on semester average score: $\geq 17$ was considered fine, 14 - 16 moderate and $<14$ poor.

Considering the magnitude of the study subject and trust to collaborate honestly in answering the questions, at first, nature and purpose of the questionnaire were explained to students and anonymity was also emphasized. Because of student's age being under 18, completing the questionnaire needed to obtain informed consent from the parents in addition to informed consent from themselves. Based on the last ethical committee, at the top of every questionnaire a short notice was brought which suggested filling it consulting their parents at home and returning without answer if they didn't wish to complete it. In the next day all questionnaires were collected in a box which was placed at the middle of the class. They were assured that their personal information would remain wholly confidential. The study was started after approval from institute's ethical committee (ID: IR.UMSHA.REC.1397.978).

The data were analyzed descriptively and analytically by SPSS 21. The frequency and percentage of responses to each question were calculated. According to the scale of the questionnaire, the total score of each individual was obtained. The normality of data distribution was checked. In order to assess relationship between sleep disorder severity and students' characteristics, Chi square test was used. Pearson correlation was considered for testing the correlation between sleep disorder and depression score and finally, in order to identify predicting factors for depression in students, logistic regression analysis was used. Variables included sex, educational situation and sleep disturbance, which had a meaningful relationship with depression in simple regression, were entered into the model and after checking the model's goodness of fit by Hosmer and Lemeshow test, predicting factors were determined. The significance level in all tests was 0.05.

\section{Results}

This study investigated 576 students in 10th to 12th grade of 1 and 2 educational areas in Hamden province. The mean age of the students was $16.53 \pm 0.69 y e a r s$ (Min - Max: 15 - 19), of whom 290 (50.3\%) were girls. 112 (19.4\%) students were studying in humanities, 319 (55.4\%) in experimental field and rest of them in mathematics. Only $5.8 \%$ (33) were without problem in sleep efficiency. Details about subscales of sleep disorder index are shown in Table 1.

Based on the results, 497 (86.3\%) participants didn't report any use of hypnotics but 5.9\%, 2.6\% and 5.2\% of them used it one time, two times and three or more times in a week, respectively. 


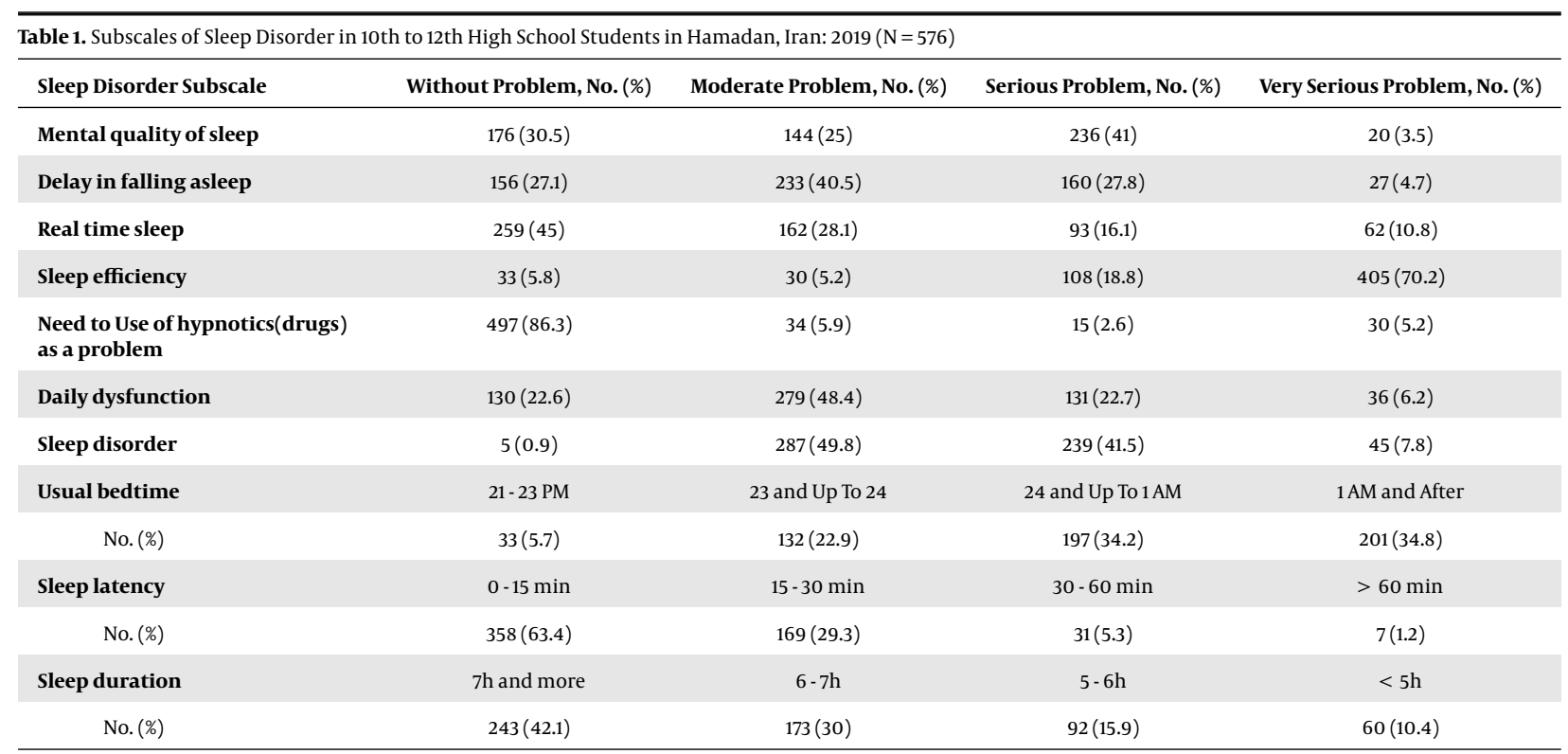

Results for association between sleep disorder severity and students characteristics showed that $12.9 \%$ of the boys and only $2.8 \%$ of the girls had severe problem of sleep disorder $(\mathrm{P}<0.001)$. In students with good educational status (Semester grade point average $\geq 17$ ) $56.6 \%$ hadn't any sleep disorder or they showed mild problems whereas $43.9 \%$ of students with moderate educational status and $40.7 \%$ of poor educational status showed moderate problems of sleep disorder $(\mathrm{P}<0.05)$. So, in girls and students with proper educational status, sleep disorders were less than others. However, there wasn't any relationship between sleep disorder severity and field of study $(\mathrm{P}=0.157)$. Details are shown in Table 2.

It was notable that among all students only 5 persons $(0.9 \%)$ were considered normal in terms of mood and without any problem in sleep. So, rest of them endured some degree of depression or sleep disturbance and sleep disorder was significantly higher in severely depressed students $(\mathrm{P}<0.001$ ) (Table 3 ).

Additionally, there was a statically significant correlation between sleep disorder and depression score (Pearson correlation: $\mathrm{r}=0.42 ; \mathrm{P}<0.001)$ which is shown in Figure 1.

In logistic regression analysis for detecting depression's predicting factors, being boy and having severe problem in sleep pattern of the students were considered as statistically related variables to depression (Table 4).

\section{Discussion}

Considering the importance of sleep disorder and its effect on mental and physical health in adolescents, this study which was designed on almost 600 Iranian adolescents to asses sleep pattern and its relationship with depression. The study revealed that nearly $70 \%$ of the adolescents had problems in mental quality of sleep, delay in falling asleep and daily dysfunction. In $10 \%$, sleep duration was less than 5 hours and in $69 \%$ usual bedtime was after midnight (24 o'clock).

Poor sleep quality has been reported in different studies from nearly half of the students $(2,23,24)$ to more than $80 \%$ in other studies (25). In our findings less than half of the students ( $42 \%$ ) had normal sleep duration $(\geq 7 \mathrm{~h}$ ) based on recommended need for adolescents (26) which was less than other findings in similar previous studies $(24,27,28)$.

It seems that these poor sleep quality and quantity indicators contribute to a huge stress for passing a contest examination for entering the university (the so-called Concours) especially in 10th to 12th high school students in Iran. The manner of setting and running this exam is associated with high stress imposed on students which is worth that educational officials and managers think about changing the method of students' evaluation for entering the university, in order to provide healthy sleep and mental health in adolescents.

Poor sleep can increase some physically problems such as blood pressure and type 2 diabetes risk in youth (9) beside psychological complications including depression, anxiety, ADHD and even suicide $(5,6,17,29)$.

The present study revealed that severe sleep problems in boys were more conspicuous than in girls and more than half of students with good educational status didn't have sleep problem. However, there wasn't any relation- 


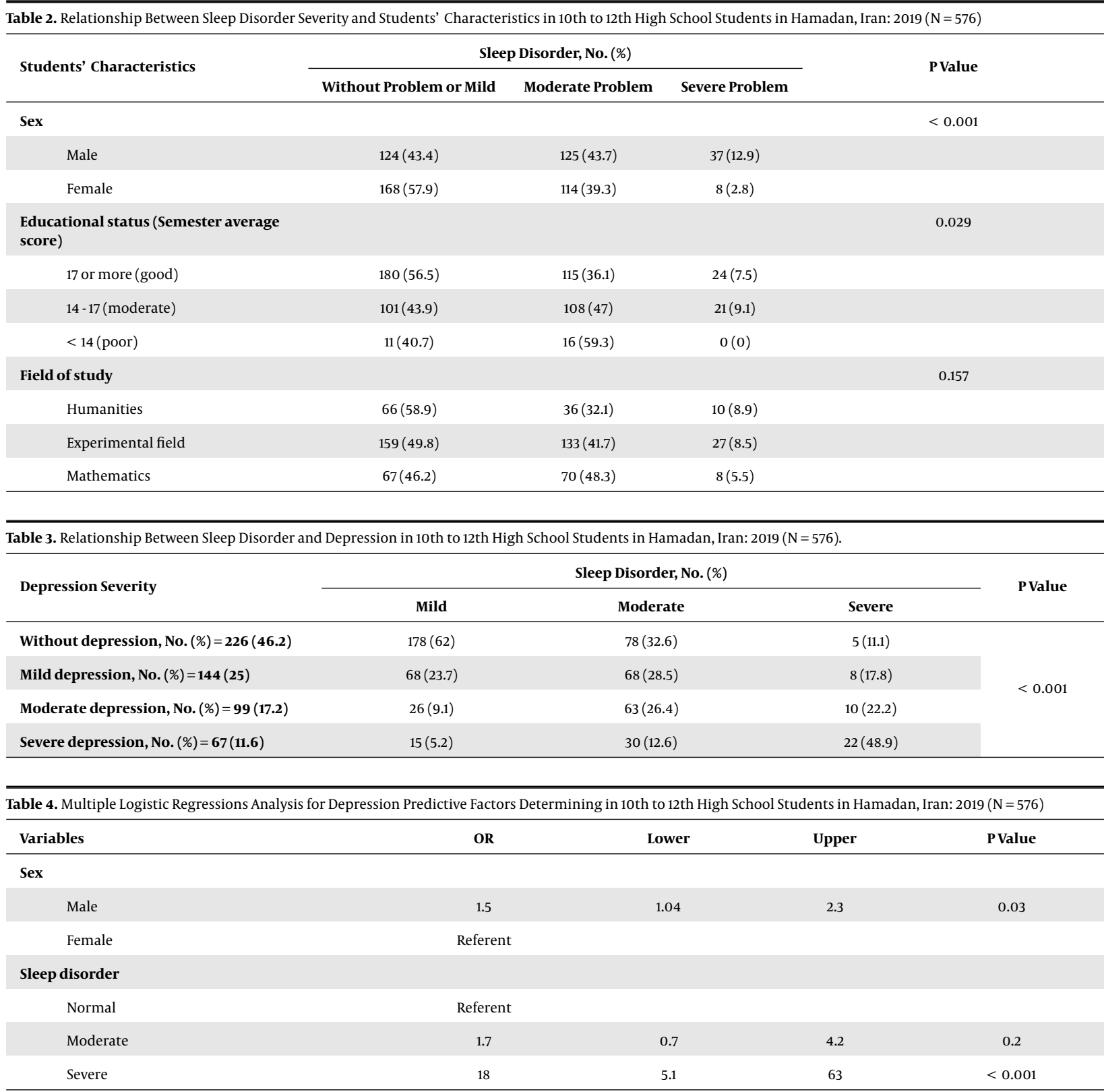

${ }^{\mathrm{a}}$ Hosmer and Lemeshow test: Chi square $(6)=3.6$, P value $=0.7$; A total of $68.6 \%$ of subjects were correctly classified

ship between sleep disorder severity and field of study. In a systematic review, female gender, depressed mood, and physical illness were considered as risks for future sleep disturbances (30). The other point that was assessed in this project was amount of using electronic devices and screens which was higher in boys in comparison with girls and using those devices showed statically significant relationship with sleep problems, as well. It might be considered as a reason for having more sleep problems in boys than in girls. Details about using electronic devices and screens will be brought in a forthcoming article.

Several psychosocial factors may affect sleep pattern and are related to the delay in bedtime and reducing the sleep duration in adolescents (31). Our findings showed statically significant correlation between sleep disorder and depression score. Association between poor sleep quality and depressive symptoms has been observed in some former studies $(5,7,17,29)$.

Several pathways have been recommended for chains of relationship between poorer sleep quality and higher 


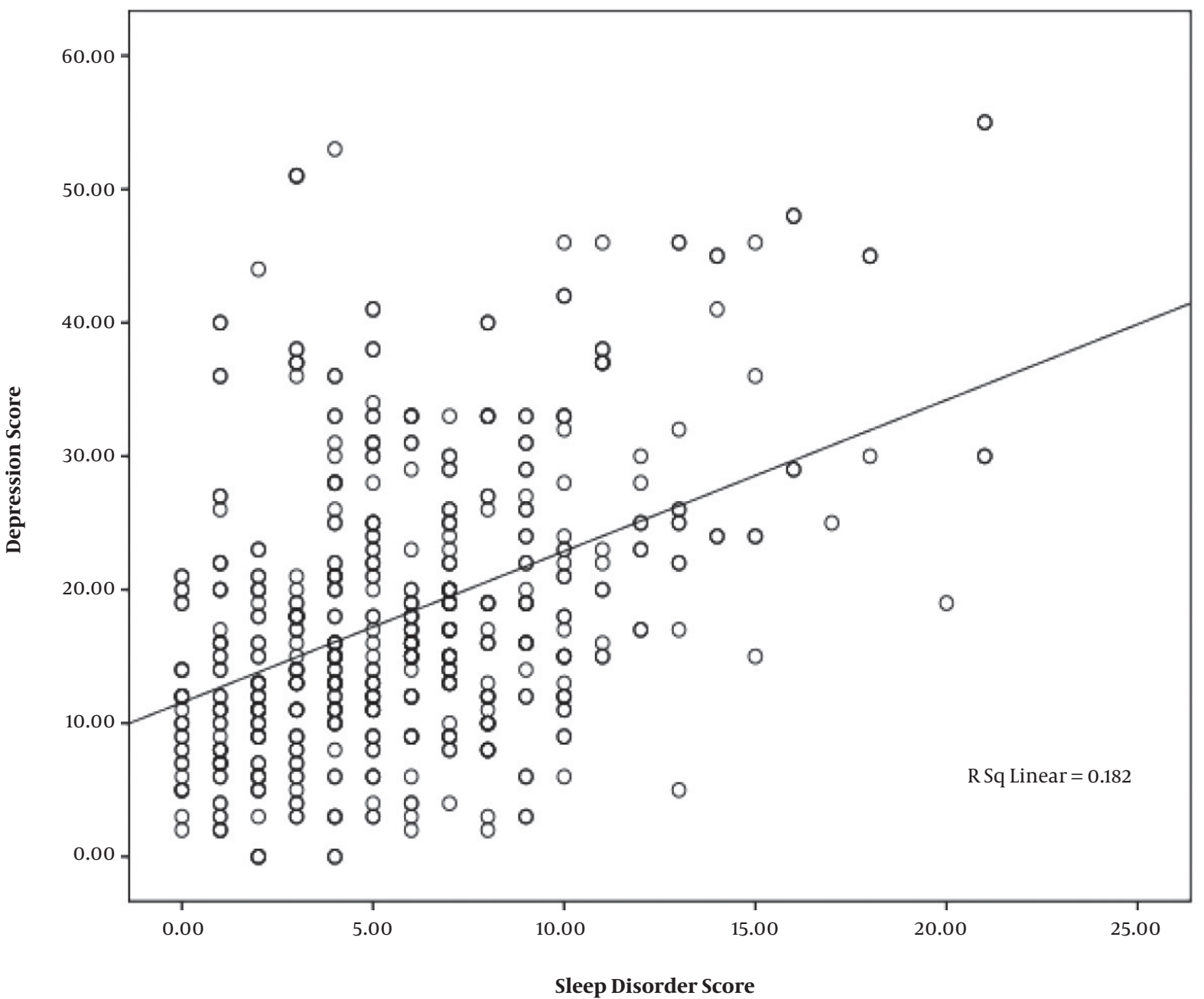

Figure 1. Relationship between sleep disorder and depression in 10th to 12th high school students in Hamadan, Iran: $2019(\mathrm{n}=576)$.

depressive symptoms $(32,33)$. Additionally, it has been explained that elevated anxiety is related to in appropriate concentrations of serotonin and dopamine in the brain (34), and those neurotransmitters have been related with sleep quality and decreased REM sleep time(35)and depressive symptoms (36).

This study revealed that nearly $70 \%$ of Iranian students had problems in mental quality of sleep, more than half of them had normal sleep duration and almost half of them had some degrees of depression symptoms. Being boy and having severe problem in sleep pattern were considered as statistically related variables for predicting depression. Of course, this was a cross -sectional study, so that we couldn't get evidential results indicating that defect in sleep pattern can cause depression, cohort studies are needed for detecting causality. However, adolescent health providers should consider how these difficulties may potentially worsen each other. So, adolescents with sleep problems should be screened for comorbid mental problems, particularly depression or even suicide and selfharm behavior. These information might be applied for well-being and physical and mental development interventional programs in adolescents' health promotion as an important age group in the future by policy makers.

\subsection{Limitations}

Our study has limitations which need to be considered in the future researches. Firstly, this is a cross-sectional study, so we cannot demonstrate causality in our interpretation; secondly, our sample was limited to adolescents in a particular population (10th to 12th high school students), so, results may not be generalized to all adoles- 
cents; thirdly, some more accurate results would be found if one-week sleep diary of the participants had been detected; fourthly the percentage for sleep problems underestimated (13.7\% in the worst situation) suggestive of hypnotics use, these cases were not separated in our analysis. It is recommended that other psychological problems such as stress, anxiety, suicide, etc. beside interventional programs for reducing the sleep problems be assessed in the future research and in adolescents health care packages.

\subsection{Conclusion}

Problems in mental quality of sleep were notable in Iranian adolescents and almost half of them had some degree of depression symptoms. Being boy and having severe problem in sleep pattern were predictors for depression. These findings might be applied to interventional programs for well-being and physical and mental development of adolescents, as well as parents' educational programs for adolescents' health promotion.

\section{Acknowledgments}

We gratefully thank all managers and staff in central department of education and all managers of high schools in Hamadan province for their help for data collection.

\section{Footnotes}

Authors' Contribution: AP conceived and designed the evaluation, interpreted the clinical data, performed the statistical analysis and drafted the manuscript and revised it. SB collected the data and SP helped to design the evaluation and draft the manuscript. All authors read and approved the final manuscript.

Conflict of Interests: The authors declare that they have no conflict of interests.

Ethical Approval: The study was started after approval from institutes ethical committee (ID: IR.UMSHA.REC.1397.978).

Funding/Support: This research is a part of medical student thesis number 98012086 and funded by Hamadan University of Medical Sciences.

Informed Consent: Obtain informed consent from the parents in addition to informed consent from themselves.

\section{References}

1. Brand S, Kirov R. Sleep and its importance in adolescence and in common adolescent somatic and psychiatric conditions. Int J Gen Med. 2011;4:425-42. doi: 10.2147/IJGM.S11557. [PubMed: 21731894]. [PubMed Central: PMC3119585].
2. Carter B, Rees P, Hale L, Bhattacharjee D, Paradkar MS. Association Between Portable Screen-Based Media Device Access or Use and Sleep Outcomes: A Systematic Review and Meta-analysis. JAMA Pediatr. 2016;170(12):1202-8. doi: 10.1001/jamapediatrics.2016.2341. [PubMed: 27802500]. [PubMed Central: PMC5380441].

3. Roessler KK, Grove S. Adolescents need more sleep: Rethinking the preventive options of school environments. Scand J Public Health. 2020;48(4):468-71. doi: 10.1177/1403494818785788. [PubMed: 30409081].

4. Hestetun I, Svendsen MV, Oellingrath IM. Sleep problems and mental health among young Norwegian adolescents. Nord J Psychiatry. 2018;72(8):578-85. doi: 10.1080/08039488.2018.1499043. [PubMed: 30296874].

5. Van Dyk TR, Becker SP, Byars KC. Rates of Mental Health Symptoms and Associations With Self-Reported Sleep Quality and Sleep Hygiene in Adolescents Presenting for Insomnia Treatment. J Clin Sleep Med.2019;15(10):1433-42. doi:10.5664/jcsm.7970. [PubMed:31596208]. [PubMed Central: PMC6778362].

6. Richardson C, Oar E, Fardouly J, Magson N, Johnco C, Forbes M, et al. The Moderating Role of Sleep in the Relationship Between Social Isolation and Internalising Problems in Early Adolescence. Child Psychiatry Hum Dev. 2019;50(6):1011-20. doi: 10.1007/s10578-019-00901-9. [PubMed: 31152375].

7. Lima RA, de Barros MVG, Dos Santos MAM, Machado L, Bezerra J, Soares FC. The synergic relationship between social anxiety, depressive symptoms, poor sleep quality and body fatness in adolescents. $J$ Affect Disord.2020;260:200-5. doi:10.1016/j.jad.2019.08.074. [PubMed: 31499376].

8. Lecendreux M, Cortese S. Sleep problems associated with ADHD: a review of current therapeutic options and recommendations for the future. Expert Rev Neurother. 2007;7(12):1799-806. doi: 10.1586/14737175.7.12.1799. [PubMed: 18052772].

9. Mokhlesi B, Temple KA, Tjaden AH, Edelstein SL, Nadeau KJ, Hannon TS, et al. The association of sleep disturbances with glycemia and obesity in youth at risk for or with recently diagnosed type 2 diabetes. Pediatr Diabetes. 2019;20(8):1056-63. doi: 10.1111/pedi.12917. [PubMed: 31486162]. [PubMed Central: PMC7199716].

10. Patel V, Flisher AJ, Hetrick S, McGorry P. Mental health of young people: a global public-health challenge. Lancet. 2007;369(9569):1302-13. doi: 10.1016/S0140-6736(07)60368-7. [PubMed: 17434406].

11. Bernert RA, Turvey CL, Conwell Y, Joiner TJ. Association of poor subjective sleep quality with risk for death by suicide during a 10-year period: a longitudinal, population-based study of late life. JAMA Psychiatry. 2014;71(10):1129-37. doi: 10.1001/jamapsychiatry.2014.1126. [PubMed: 25133759]. [PubMed Central: PMC4283786].

12. Goldstein TR, Bridge JA, Brent DA. Sleep disturbance preceding completed suicide in adolescents. J Consult Clin Psychol. 2008;76(1):84-91. doi: 10.1037/0022-006X.76.1.84. [PubMed: 18229986]. [PubMed Central: PMC2823295].

13. Bernert RA, Nadorff MR. Sleep Disturbances and Suicide Risk. Sleep Med Clin. 2015;10(1):35-9. doi: 10.1016/j.jsmc.2014.11.004. [PubMed: 26055671].

14. Motomura Y, Kitamura S, Oba K, Terasawa Y, Enomoto M, Katayose Y, et al. Sleep debt elicits negative emotional reaction through diminished amygdala-anterior cingulate functional connectivity. PLoS One. 2013;8(2). e56578. doi: 10.1371/journal.pone.0056578. [PubMed: 23418586]. [PubMed Central: PMC3572063].

15. Moore M, Kirchner HL, Drotar D, Johnson N, Rosen C, Ancoli-Israel $\mathrm{S}$, et al. Relationships among sleepiness, sleep time, and psychological functioning in adolescents. J Pediatr Psychol. 2009;34(10):1175-83. doi: 10.1093/jpepsy/jsp039. [PubMed: 19494088]. [PubMed Central: PMC2782255]. 
16. Solheim B, Langsrud K, Kallestad H, Engstrom M, Bjorvatn B, Sand T. Sleep structure and awakening threshold in delayed sleep-wake phase disorder patients compared to healthy sleepers. Sleep Med. 2018;46:61-8. doi: 10.1016/j.sleep.2018.03.001. [PubMed: 29773213].

17. Urrila AS, Kiviruusu O, Haravuori H, Karlsson L, Viertio S, Suvisaari J, et al. Sleep symptoms and long-term outcome in adolescents with major depressive disorder: a naturalistic follow-up study. Eur Child Adolesc Psychiatry. 2020;29(5):595-603. doi:10.1007/s00787-019-01436z. [PubMed: 31696307]. [PubMed Central: PMC7250797]

18. Owens JA. Sleep in children: Cross-cultural perspectives. Sleep Biol Rhythms. 2004;2(3):165-73. doi:10.1111/j.1479-8425.2004.00147.x.

19. de Lijster JM, Dieleman GC, Utens E, Dierckx B, Wierenga M, Verhulst FC, et al. Social and academic functioning in adolescents with anxiety disorders: A systematic review. J Affect Disord. 2018;230:108-17. doi: 10.1016/j.jad.2018.01.008. [PubMed: 29407534]

20. Early MC, Biggs BK, Makanui KP, Legerski JP, Van Allen J, Elledge AR, et al. Specificity of peer difficulties to social anxiety in early adolescence: categorical and dimensional analyses with clinical and community samples. Anxiety Stress Coping. 2017;30(6):647-60. doi 10.1080/10615806.2017.1348296. [PubMed: 28689447].

21. Farrahi Moghaddam J, Nakhaee N, Sheibani V, Garrusi B, Amirkafi A. Reliability and validity of the Persian version of the Pittsburgh Sleep Quality Index (PSQI-P). Sleep Breath. 2012;16(1):79-82. doi 10.1007/s11325-010-0478-5. [PubMed: 21614577].

22. Wang YP, Gorenstein C. Psychometric properties of the Beck Depression Inventory-II: a comprehensive review. Braz J Psychiatry. 2013;35(4):416-31. doi: 10.1590/1516-4446-2012-1048. [PubMed: 24402217].

23. Hoefelmann LP, Silva KS, Filho VCB, Da Silva JA, Nahas MV. Behaviors associated to sleep among high school students: cross-sectional and prospective analysis. Revista Brasileira de Cineantropometria e Desempenho Humano. 2014;16(0):68. doi: 10.5007/1980-0037.2014v16s1p68.

24. Akcay D, Akcay BD. The influence of media on the sleep quality in adolescents. Turk J Pediatr. 2018;60(3):255-63. doi 10.24953/turkjped.2018.03.004. [PubMed: 30511537].

25. Simșek Y, Tekgül N. Sleep Quality in Adolescents in Relation to Age and Sleep-related Habitual and Environmental Factors. Adolescence. 2019;2:5-7.

26. Hirshkowitz M, Whiton K, Albert SM, Alessi C, Bruni O, DonCarlos L, et al. National Sleep Foundation's sleep time duration recommendations: methodology and results summary. Sleep Health. 2015;1(1):40-3. doi: 10.1016/j.sleh.2014.12.010. [PubMed: 29073412].
27. Mak YW, Wu CS, Hui DW, Lam SP, Tse HY, Yu WY, et al. Association between screen viewing duration and sleep duration, sleep quality, and excessive daytime sleepiness among adolescents in Hong Kong. Int J Environ Res Public Health. 2014;11(11):11201-19. doi: 10.3390/ijerph111111201. [PubMed: 25353062]. [PubMed Central: PMC4245609].

28. Gamble AL, D'Rozario AL, Bartlett DJ, Williams S, Bin YS, Grunstein $\mathrm{RR}$, et al. Adolescent sleep patterns and night-time technology use: results of the Australian Broadcasting Corporation's Big Sleep Survey. PLoS One. 2014;9(11). e111700. doi: 10.1371/journal.pone.0111700. [PubMed: 25390034]. [PubMed Central: PMC4229101].

29. Bernert RA, Kim JS, Iwata NG, Perlis ML. Sleep disturbances as an evidence-based suicide risk factor. Curr Psychiatry Rep. 2015;17(3):554. doi: 10.1007/s11920-015-0554-4. [PubMed: 25698339]. [PubMed Central: PMC6613558].

30. Smagula SF, Stone KL, Fabio A, Cauley JA. Risk factors for sleep disturbances in older adults: Evidence from prospective studies. Sleep Med Rev. 2016;25:21-30. doi: 10.1016/j.smrv.2015.01.003. [PubMed: 26140867]. [PubMed Central: PMC4506260].

31. Carskadon MA. Sleep in adolescents: the perfect storm. Pediatr Clin North Am. 2011;58(3):637-47. doi: 10.1016/j.pcl.2011.03.003. [PubMed: 21600346]. [PubMed Central: PMC3130594].

32. Burke AR, McCormick CM, Pellis SM, Lukkes JL. Impact of adolescent social experiences on behavior and neural circuits implicated in mental illnesses. Neurosci Biobehav Rev. 2017;76(Pt B):280-300. doi: 10.1016/j.neubiorev.2017.01.018. [PubMed: 28111268].

33. Coffey SF, Banducci AN, Vinci C. Common Questions About Cognitive Behavior Therapy for Psychiatric Disorders. Am Fam Physician. 2015;92(9):807-12. [PubMed: 26554473].

34. Lanzenberger RR, Mitterhauser M, Spindelegger C, Wadsak W, Klein N, Mien LK, et al. Reduced serotonin-1A receptor binding in social anxiety disorder. Biol Psychiatry. 2007;61(9):1081-9. doi: 10.1016/j.biopsych.2006.05.022. [PubMed:16979141].

35. Mendelson M, Borowik A, Michallet AS, Perrin C, Monneret D, Faure P, et al. Sleep quality, sleep duration and physical activity in obese adolescents: effects of exercise training. Pediatr Obes. 2016;11(1):26-32. doi: 10.1111/ijpo.12015. [PubMed: 25727885]

36. Albert PR, Benkelfat C. The neurobiology of depression-revisiting the serotonin hypothesis. II. Genetic, epigenetic and clinical studies. Philos Trans R Soc Lond B Biol Sci. 2013;368(1615):20120535. doi: 10.1098/rstb.2012.0535. [PubMed: 23440469]. [PubMed Central: PMC3638388]. 